\title{
La vacuna cuadrivalente fue eficaz contra el Virus del Papiloma Humano para prevenir enfermedades anogenitales
}

\author{
Quadrivalent HPV vaccine is efficacious for the prevention of HPV related anogenital lesions
}

Garland SM y col. N Engl J Med 2007;356: 1928-43

\section{Objetivo}

Evaluar la eficacia de la vacuna cuadrivalente para prevenir enfermedad anogenital asociada a los serotipos $6,11,16$ y 18 de Virus del Papiloma Humano (HPV).

\section{Diseño}

Ensayo clínico aleatorizado.

Lugar

62 centros de 16 países.

\section{Pacientes}

Seguimiento durante tres años de 5455 mujeres de 16 a 24 años con menos de cinco parejas sexuales, no embarazadas y sin antecedentes de verrugas genitales o anormalidades en la citología cervical.

\section{Intervención}

Fueron aleatorizadas a recibir vacuna $(n=2723)$ o placebo $(n=2732)$ en tres dosis $(0,2$ y 6 meses $)$.

\section{Medición de resultados principales}

Incidencia de verrugas anogenitales, neoplasia intraepitelial vulvar o vaginal ó cáncer asociado al serotipo de la va-cuna; y neoplasia intraepitelial cervical, adenocarcinoma in situ o cáncer asociado al serotipo de la vacuna. Se hicieron tres análisis de acuerdo a las participantes conside-radas "vacunadas": 1) quienes efectivamente recibieron las tres dosis según el cronograma asignado; 2) la vacunadas "sa-tisfactoriamente" para la "práctica clínica real" (ej. falta o atraso de alguna dosis); 3) por intención de tratar*.

\section{Resultados principales}

Se resumen en la tabla de acuerdo a la estrategia de análisis.

Tabla:

\begin{tabular}{|c|c|c|c|c|c|}
\hline \multicolumn{2}{|c|}{ Incidencia } & Vacunadas & $\begin{array}{c}\text { No } \\
\text { vacunadas }\end{array}$ & $\begin{array}{c}\text { RRR } \\
\text { (IC95\%) }\end{array}$ & $\begin{array}{l}\text { NNV } \\
\text { (IC95\%) }\end{array}$ \\
\hline \multirow{3}{*}{$\begin{array}{l}\text { Vacunadas } \\
\text { satisfactoriamente } \\
\text { para la práctica } \\
\text { clinica real } \\
(n=2667) \text { vs. el } \\
\text { resto }(n=2684)\end{array}$} & $\begin{array}{l}\text { Lesiones anogenitales } \\
\text { y vaginal }\end{array}$ & $4(0,15 \%)$ & $81(3,01 \%)$ & 95 (87-99) & $34(29-45)$ \\
\hline & Lesiones cervicales & $2(0,074 \%)$ & $89(3,31 \%)$ & $98(90-99)$ & $30(26-38)$ \\
\hline & $\begin{array}{l}\text { CIN2, CIN3, } \\
\text { adenocarcinoma }\end{array}$ & $0(0 \%)$ & $58(2,16 \%)$ & 100 (86-99) & $46(37-63)$ \\
\hline \multirow{3}{*}{$\begin{array}{l}\text { Intención de } \\
\text { vacunar }(n=2723) \\
\text { vs. asignadas a } \\
\text { placebo }(n=2732)\end{array}$} & $\begin{array}{l}\text { Lesiones anogenitales } \\
\text { y vaginales }\end{array}$ & $28(1,02 \%)$ & $\mid 102(3,73 \%)$ & $73(58-82)$ & $37(29-53)$ \\
\hline & $\begin{array}{l}\text { Lesiones cervicales } \\
\text { (CIN1) }\end{array}$ & $71(2.6 \%)$ & $155(5,67 \%)$ & $54(40-66)$ & $32(24-50)$ \\
\hline & $\begin{array}{l}\text { CIN2, CIN3, } \\
\text { adenocarcinoma }\end{array}$ & $76(2,79 \%)$ & $101(3,69 \%)$ & $24(12-43)$ & 110 \\
\hline
\end{tabular}

NNV: número necesario vacunar para evitar un evento.

\section{Conclusiones}

La administración efectiva de al menos dos dosis de vacuna cuadrivalente contra HPV tiene una efectividad de 95\% para prevenir lesiones anogenitales externas y vaginales, y de $100 \%$ para prevenir adenocarcinoma.

Palabras claves: vacuna contra HPV, lesiones anogenitales, lesiones cervicales uterinas.

Keywords: HPV vaccine, anogenital lesions, uterine cerviz lesions. Fuente de financiamiento: Merck Research Laboratorios.

\section{Comentario}

Este estudio aporta más evidencia a la que ya existía ${ }^{1}$ de que tanto la vacuna cuadrivalente (MSD) como la bivalente (GSK) son eficaces para prevenir lesiones anogenitales producidas por HPV. Se observaron beneficios tanto en la población efectivamente vacunada como en la población asignada a recibir vacuna.

La vacuna ya está comenzando a ser recomendada en Europa y EE.UU., siendo la población blanco sugerida niñas de 11 y 12 años antes de comenzar las relaciones sexuales (población ideal) y sugiriéndose también vacunar a las mujeres desde los 13 hasta los 25 años ya que también sería beneficiosa en este grupo.

Ya se encuentra disponible en Argentina y muchas de los financiadores cubren un porcentaje de la misma. Las contraindicaciones son hipersensibilidad a algunos de los componentes y cursar una infección grave y aguda con fiebre.

La vacuna cuadrivalente es realmente eficaz para prevenir las lesiones anogenitales producidas por el HPV. Si bien todavía faltan estudios para poder recomendarla a nivel masivo, a partir de los resultados de este estudio se podría suponer que aplicarla sería una buena estrategia de salud pública. Un punto aún controvertido es la duración del efecto de la vacuna. Se observó en un estudio fase II que el tiempo aproximado en el que se mantendrían títulos protectores es de cinco años.

\section{Conclusiones del comentador}

Es importante remarcar que como existen otras técnicas efectivas de rastreo como el test de papanicolaou ${ }^{2,3}$, habría que considerar cada situación particular antes de hacer cualquier recomendación formal y trasmitir a los pacientes que el cuidado de la salud no es inadecuado en quienes no se apliquen la vacuna. Por otro lado, estudios de costo-efectividad locales permitirán evaluar mejor su valor.

Ver glosario*

Tamara Sigal y Gonzalo Yamauchi Quintian [ Servicio de Medicina Familiar y Comunitaria, Hospital Italiano de Buenos Aires. ]

Sigal T, Yamauchi Quintian G. Evid. actual. práct. ambul; 10(5):134, Sep-Oct.2007. La vacuna cuadrivalente contra el Virus del Papiloma Humano fue eficaz para prevenir enfermedades anogenitales. Comentado de: Garland SM, Hernandez-Avila M, Wheeler CM, et al. Quadrivalent Vaccine against Human Papillomavirus to Prevent Anogenital Diseases.N Engl J Med 2007;356: 1928-43. PMID: 17494926

Referencia

1. Rambout L. Prophylactic vaccination against human papillomavirus infection and disease in women: a systematic review of randomized controlled trials.

CMAJ. 2007 Aug 28;177(5):469-79.

2. Agosti J.Introducing HPV Vaccine in Developing Countries - Key Challenges and Issues. N Engl J Med 2007;356:1908-1910

3. Cannistra S. Cancer of the Uterine Cervix. N Engl J Med 1996; 334:1030-1037. 